\title{
The Criticism of the EFL textbook Taught at Iraqi Public secondary school
}

\author{
Dr. Hayder K. H. Al Hamdany \\ Department of English Language \\ The University of Kufa
}

Email: hayderk.alhamdany@uokufa.edu.iq

\begin{abstract}
:
Curriculum criticism is a systematic way to develop and account for programmatic action that involves procedures that are useful, practicable, ethical and accurate for the anticipated users of criticism process and findings (Patton, 1997 cited in Watanabe 2006). This article critiques an EFL textbook which has been prescribed for use in Iraqi secondary schools. First, a general definition of curriculum will be given. Following, an analysis of the target text book will show how the target learners, teachers and their community (culture) are represented in. The article then gives some suggestions as to how to alleviate some of shortcomings encountered in this textbook.
\end{abstract}

\section{Introduction :}

Stenhouse (1975 cited in Barnett 2009) emphasises on communicating "the essential principles and features of an educational proposal such that it is open to critical scrutiny and capable of effective translation into practice" (p. 4). By dissimilarity, White (1988 cited in Barnett 2009), talking about ELT (English Language Teaching) curriculum, emphasises the "totality of content to be taught and aims to be realized within one school or educational system," using the analogy of curriculum as "a plan of how to build a house" (p. 6). So, while Stenhouse includes pedagogical principles, White's view is limited to content.

Nunan (1988 cited in Barnett 2009) states that the curriculum of a given institution or language program can be viewed both as a statement of intent - "what should be" in terms of outlines, objectives, and other planning documents - or as a "reality" in terms of what actually goes on from moment to moment in the language classroom (p. 172). In other words, Nunan differentiates curriculum-as-document 
from curriculum-as-action, whereas Stenhouse and White were only talking about curriculum-as-document or pre-requisite course content, for which the term "syllabus" is regularly employed. Curriculum-asaction can be seen as "the range of experiences that learners have under the auspices of an educational organisation" (Bottomley et al. 1995, p. 2 cited in Barnett 2009). Print (1993 cited in Richard 2001), attempts to join curriculum-as-document and curriculum-as-action, by defining curriculum "as all the planned learning opportunities offered to learners by the educational institution and the experiences learners encounter when the curriculum is implemented" (p. 9). In one word, this seems to accomplish the goal.

\section{The context :}

\section{English language in Iraq}

From 1920 until present day, the major language of international communication for the Republic of Iraq is English. English has become the first foreign language. In recent years, Iraq has seen an explosion in the demand for English. With the move to a market economy by the Iraq government and the growth of international business as well as an increasing number of multinational forces which are working in Iraq, knowledge of English has become the passport to a better paid job not only in the business companies and hospitality industries, but in many other enterprises. English is taught in primary/ secondary schools, universities, and evening classes across the country.

The provision of English language instruction at secondary level in Iraq. Iraqi general education consists of 12 grades: primary school (from grade 1 to 6: for children aged 6 to 12); junior secondary school (from grade 1 to 3 sometimes 4: for children aged 12-15/16); and senior secondary school (from grade 4 sometimes 5 to 6: for children aged 16-18). Foreign language (English) is taught to children from grade 5: primary school. As far as English is concerned, there is considerable provision for English language teaching and learning at secondary level. The teaching of English is now established in almost all primary and secondary schools in 18 provinces and cities throughout Iraq, without any exception of a number of schools located in the remote rural areas and in the highlands where there is still a 
shortage of teachers of English. Students learn English for four-five 45-minute periods a week (Iraqi Ministry of Education, 2009).

\section{The goals}

It is generally implicit that after approximately 700 class hours in seven years of studying, students should have mastered basic English phonetics and grammar, and to know a minimum of around 2,000 vocabulary items of English. Theoretically, students should have developed a certain level of proficiency in the four skills and be able to read materials at the same level as their textbook using a dictionary. Although there is no official written government policy on English language teaching for the formal education system in Iraq, there is a document as a teachers' guide on English language curriculum goals issued by the Ministry of Education which reflects the government language policy.

According to this document, the aims and objectives of the Iraqi secondary school ELT

curriculum and textbooks are as follows:

1. To develop students' ability to read English text

2. To develop students' basic ability to write and enable them to use English to literary show their ideas and/or ideas.

3. To develop students' listing and speaking capabilities and guide them to produce suitable manners of speaking

4. To lead students in the correct ways of writing characters and enable them to write with accuracy, tidiness. And so on.

\section{The textbook under study :}

Hamash,Kh., et al, (2001). English Book 6. Baghdad: Textbook Publishing company ofies Iraq. This is an official textbook which has been prescribed for use in all Iraqi secondary schools by the Ministry of Education. It is a compulsory subject for the four grade students in senior secondary school.

\section{Aims and Objectives :}

Like any textbook, the aim of the textbook under research must reflect the proper choosing of materials and also must be the device of the successful completion of the objectives (outlined in Roman 
numerals). Due to space constraints, only grammatical aims and objectives are included here...

I. Textbook Aim: Students will achieve a basic level of listening and speaking skills in English.

A. Students will comprehend and produce basic English lexical and grammatical forms.

i. Students will have a reading vocabulary of over 200 common nouns and over 30 common verbs.

ii. Students will understand and use present, past and future notions of time in a controlled manner.

iii. Students will memorize and understand scripted dialogs pertaining to events common to their age.

iv. Students will understand and produce most forms of prepositions, demonstrative pronouns, and count and non-count nouns.

v. Students will answer random but appropriate questions based on the content and context of the previous four objectives.

B. Students will build listening skills and pronunciation (as an audiolingual conjunct to aim one).

i. Students will have a listening vocabulary of over 200 common nouns and over 30 common verbs.

ii. Students will listen to and produce present, past and future notions of time in a controlled manner.

iii. Students will listen to and produce scripted dialogs pertaining to events common to their age.

iv. Students will listen to and produce most forms of prepositions, demonstrative pronouns, and count and non-count nouns.

C. Students will utilize creativity and critical thought using various tasks in English.

i. Students will explore and talk about the grammatical rules for present, past and future notions of time in a series of awareness raising activities.

D. Students will build up intelligibility in the understanding and creation of pronunciation on both the segmental and suprasegmental levels.

i. Students will differentiate between and make similar consonant and vowel sounds in a minimal pairs activity. 
ii. Students will differentiate between word final epenthesis and correct pronunciation of words and produce the proper forms in a controlled production exercise.

\section{Curriculum and students' and teachers' needs}

Tudor (2001) states that students are not 'simply' language learners but complex human beings whose interaction with the language study is influenced by variety of attitudinal and experiential factors. Within this framework, students are seen primarily as a social actor whose identity is defined in terms of social role in which they would have to use language, e.g. a tourist needing, a student needing to read a certain special material, a student needing to pass an exam to obtain a higher education level, and so on. In this case, the curriculum should focus on one hand, the skills which the learners need and the outcome of the learning, on the other hand, the curriculum authors should take into account the individual differences among learners. Individual differences are those factors of psychological, cognitive or attitudinal nature which influence the way in which learners perceive and interact with their language study. Individual differences studied with respect of to second or foreign language learning include motivation (Dornyei,1990,1994, 1998 cited in Tudor 2001), anxiety (Scovel, 1978, cited in Tudor 2001), tolerance for ambiguity (Chapelle and Roberts, 1986 cited in Tudor 2001), and field dependenceindependence (Abraham, 1985, cited in Tudor 2001).

However, Bruner (1966 cited in Richard 2001) argued that the curriculum should focus less on the outcomes of the learning and more on the knowledge and skills learners needs to develop. These include the concept of children should acquire through the process of inquiry and deliberation. Stenhouse (1975 cited in Rechard 2001) stated that the curriculum should focus on activities that engage the student in such process as investigation, decision making, reflection, discussion, interpretation, making choice, cooperation with others, and so on.

In Book 6, our target textbook, there is an emphasis on knowledge and skills learners need to develop rather than the learning outcomes. Students are expected to show their abilities to read and write and listen and speak. One of these skills is an ability to read English, for example part (A) of the introduction in teachers' guide is 
concerned with why the section "New Vocabulary" is included in the book and how it must be introduced by the teachers. It reads, 'the objective of this section is to familiarize learners with the new vocabulary in the reading comprehension section'. However, this is not implemented in the book because the number of new words introduced in the New Vocabulary Section is considerably less than the number of new words in the readings comprehension section. These new words are easy to comprehend by some students because they have a motivation to learn new words but at the same time it difficult to the rest of the class to catch. These are individual differences among students which are not taken into consideration when the textbook was written, this textbook for all Iraqi secondary school in urban and rural areas and for students who has motivation and anxiety to learn English and for those who have less or no motivation to learn English. In this case students need to be enjoyed and motivated by the curricula. To know to what extent that the teachers' and learners' needs are represented in this textbook, we need to look at some aspects in such as textbook.

\section{Interesting topics and tasks in Book 4}

The topics of readings differ from real to anecdotal, and sometimes are funny stories. It is difficult to judge on behalf of students whether they interesting or not for them. And it needs research. However, the majority of the topics give the impression to be attractive to the learners in EFL classes. However, it seems that it would be better if the topics were modernized to become more matching with the taste of the new generation which might be a bit different from that of the authors who designed the book at least ten years ago, currently, learners' needs are different from what they used to be and hence it looks better to comprise text more linked to computer games, the internet, and satellite programs. For instance, it is possible to take and adapt some of the texts, words and jargon which are currently used in information technology. It is also possible to comprise adapted and simplified some versions or quotations and saying of scholars renowned for their wisdom and eloquence in line with higher culturally valued objectives of education such as trustworthiness, courage, sacrifice, etc. My personal experience shows that the meaning and content of material taught in English 
classes has strong and long-lasting impacts on the minds of the learners. This is a valuable opportunity if we want to educate them mentally and spiritually. It has observed that the story of "Kipps" in Book 6 attracts the students more than the story of Mrs and Mr. Corry.

\section{Clear instruction}

Most of the instructions are clear and easy to understand for the learners in the target textbook in the series. Even if the learners might not well-known with the structures and lexis used in the instructions, the models given for each group of exercises provide contextual clues for the learners as to what they are expected to do. However, some of instructions are deficient in the required contextual information and also may be beyond many of the learners' English language proficiency in terms of linguistics complexity. For instance, Book6, lesson4, the instruction reads: "Write eight sentences in passive four about what happened in the past and four about what will happen in the future." One possible solution might be to use the learners' native language instead of the target language in the instructions.

\section{Duration}

The time students need to learn and practice new vocabulary, and new ways of making meaning, lends itself to units of greater length. The book has 18 units. A unit of longer than two weeks enables the learners to consolidate, expand and incorporate new vocabulary and language structures into their productive repertoire. This enables the student to respond to and compose more sophisticated texts with increasing confidence and independence. Rapid changes in topic and unit focus can lead to excess and prevent students from increasing self-assurance and mastery in utilizing the new language and method of using language.

\section{Grammar presentation and practice in the target textbook}

Grammar drills take up the lion's share of each lesson and variety from repetition, substitution to transformation ones. They are intended at providing the learners with oral practice of intended grammatical points. The oral drills are techniques which were utilized in Audio-Lingual method and similar approaches to second language teaching for various pedagogical purposes one of which was 
automatiztion can be viewed from two perspectives: one is to build up the ability to give quick and in-time responses to particular verbal stimuli mainly in phatic communion. The second is to build up the ability to process a given piece of information without awareness or attention, making relatively more use of long-term memory. For example, to produce a particular sentence according to the grammatical rules of a language. However, because the so-called standard tests that are usually administered by the officials of the Ministry of Education are almost completely lacking in test items measuring the productive ability of the learners, the teachers, for this or may be some other rezones, usually omit the drills and change them with the explicit explanation of the rules and formulas.

\section{Practice in all four skills}

The target book has devoted a large proportion of the lessons to materials that primarily aim at the developing and enhancing the reading ability of the learners. bearing in mind the idea that the main needs of the learners might be to obtain a suitable degree of mastery and skill in reading materials written in English, this allocation looks justified. However, neither in the introduction nor in the lessons has it been explicitly mentioned by the writer of the target book how to treat listening comprehension and writing skills. It is completely left to the teachers to make a decision whether to perform it or not. There is no section in the lessons specially designed to develop enhance listening skills in the learners. However, the teachers can possibly work on this skill through having the learners listen to the reading passages read aloud by the teachers or other learners in the classroom. To engage the learners actively and attentively to listen to the passages read aloud, the teacher can ask a variety of comprehension questions at different points or at the end of the listening activity to make sure their understanding. The speaking skill is also taken into account though indirectly and as a marginal activity. There are certain questions at the end of each reading passage which need the learners to give oral answers.

The last but not the least is the writing skill. If we describe the writing skill as the ability to communicate one's feelings and thoughts to exacting person or group of addressees through the orthography from of a language, it is possible to say that it somehow neglected in 
the series. even though some exercises of the lessons are proposed to enhance the writing skills of the learners, they are limited to a few isolated sentences production activities to sense which was propose above. The authors could have included writing activities in different formats varying from controlled to free writing according to the proficiency level of the learners.

Consequently, teachers teach in a way so that their students can pass the exam which is at the final year of secondary school education and university education rather than executing the actual curriculum worked out by the academic specialist.

This book was written for qualified teachers who can create implicit and explicit ideas from this book. Bell (1998) states that teachers should integrate the four skills throughout and that the "receptive skills" of reading and listening should not be tagged on the after-language work. Language use is a combined skilled where everything depends on everything else-at the very least learners listen and speak together and read and write together. According to that, the teachers could have flexibility moving activities around, cut them out or supplement them according to need, like what teachers did with drills which mentioned beforehand. By doing so, the teachers need to engage the students in a specific context.

There are some readings in $\mathrm{B} 6$ which provide interest from a specific British context and stimulate culture and personal comparison. For example, "Kipps" story, the teachers could use this text to engage the students personally. At the same time, the text can be used as a resource for language.

Woods (1991 cited in Tudor 2001) suggests that the reality of the classroom teaching is not what is found in official curricula or recommended materials, but results from individual teachers' interpretations of these. The official textbook certainly does influence what takes place in the classroom, but not in a linear or easily predictable manner. The reality of classroom teaching and learning emerges from the teachers' interpretation of the textbook or materials in use; this interpretation interacts with perceptions of the learners involved, as well as with forces present in the broader context in which teaching is conducted.

Bell (1998) states that one of the "dangerous" of some kinds of publications are that many of culture contexts in the materials and 
text- topics can seem irrelevant to the learners. The materials inevitably lack the targeting to the specific learning situations in a particular culture. This may be more marked when learners are studying in their home culture, where their own socioculturally based beliefs and expectations receive reinforcement from the attitudes and behaviour from other participants (including their teachers) as well as from various institutionalised aspects of the education system. All these issues were taken into account by the authors of the target textbook (B6) when they tried to avoid the topics, films, stories which are not welcomed by Arabic culture. For example, in the dialogue activity, the textbook gives a dialogue or more for each unit. In each dialogue, we have two roles (sometimes more) which often express an Iraqi situation (not the English one). This is often expressed by two interlocutors. The culture expressed in the dialogue is the Arabic culture not the English one, at the same time this may create an important gap in the learning process because learners of English as a foreign language, and any other foreign language, must study English, and any other language, along with its culture. We cannot understand any language estranged from its culture. Language is to be taken as one of the manifests of culture or language is taken to be culture.

\section{Conclusion :}

EFL textbook can play an important role in the success on language programs. In fact, they are the awareness of the processes of means/ends specification in the curriculum planning. Sheldon (1988) states that, "Textbooks represent the visible heart of any EFL program" (p.237). They afford the objectives of language learning: They function as a lesson plan and working agenda for teachers and learners. Cunningsworth (1995) suggests that textbooks are a useful resource for self-directed learning, a useful resource for presentation materials, a source of ideas and activities, and a reference source for students, syllabus where they reflect pre-determined learning objectives, and support for less experienced teachers who have yet to gain in confidence. 


\section{References:}

Barnett, J 2009, Online study guide, University of South Australia, viewed 6 September 2009, https://my.unisa.edu.au/unisanet/learn/UniSAnet1/?PATH=/Resources/100951/Curriculum+online+resources/\&default=Wel come.htm

Bell, J. and Gower, R. (1998). Writing course material for the world: a great compromise. In B. Tomlinson (ed) Materials development in language teaching. Cambridge: Cambridge University Press, pp; 116-129. Cunningsworth, A. (1995). Choosing Your Coursebook. Oxford: Heinemann.

Ministry of Education (2000). Curriculum Goals for English Language Instruction in Iraqis secondary schools (in Arabic). Baghdad: Ministry of Education.

Richards, J. C. (2001). Planning goals and learning outcomes. Curriculum Development in Language Teaching. Cambridge University Press pp. 112144.

Sheldon, L. (1998). Evaluating ELT textboos and materials. ELT Journal, 42 (4), 237-246.

Tudor, I. (2001). A changing prespective on language teaching. The dynamic of the language classroom. Cambridge: Cambridge Unversity Press, pp. 5-12.

Watanabe, Y. (2006). A need analysis for a Japanese high school EFL general education curriculum, University of Hawai'i at Manoa. 
نقد كتاب تعليم اللغة الإنجليزية كلغة أجنبية

يدرس في المدرسة الثانوية العامة العراقية

$$
\text { دامعة الكوفة ـ قريم اللغة الانكليزية }
$$

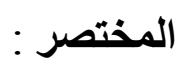

نقد المناهج الدراسية هو طريقة منهجية لتطوير وحساب العمل البرنامجي الذي يتضمن

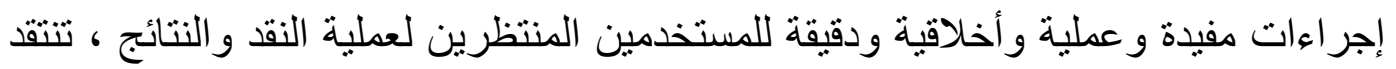
هذه الدقالة كتابًا باللغة الإنجليزية كلغة أجنبية نم وصفها للاستخدام في الددارس الثانوية

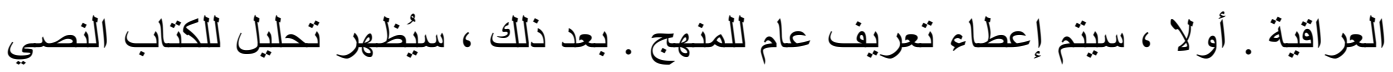
المقصود وكيف يتم تمثيل المتعلمين المستهدفين و المعلمين ومجتمعهم (الثقافة). تقام المقالة بعض الاقتر احات بشأن كيفية التخفيف من بعض أوجه القصور التي تمت مواجهنها في هذا

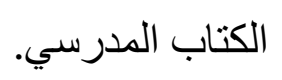

